\title{
Research on Application of SWOT Analysis Model in Chinese Professional League
}

\author{
Yanjing Pan ${ }^{1, a}$, Changhong $\mathrm{Xu}^{2, \mathrm{~b}}$ and Honghong Yang ${ }^{3, \mathrm{c}}$ \\ ${ }^{1}$ Institute of Physical Education, YunNan Normal University, Kunming \\ 650500, China; \\ ${ }^{2}$ Institute of Physical Education, YunNan Normal University, Kunming \\ 650500, China; \\ 3 Institute of Art, YunNan Normal University, Kunming \\ 650500, China; \\ a704019088@qq.com,b1531419886@qq.com,cbbyhyanghonghong@163.com
}

Keywords: SWOT analysis model; Chinese Football Association Super; Application and Research.

\begin{abstract}
In this paper, through the SWOT method of Chinese professional league operation analysis model. To Super League operating mode of this example for research. The paper analyzes the advantages and disadvantages of SWOT, analyzes the key contents and important conditions of SWOT analysis model, After summarizing the analysis of the samples, this paper puts forward the solutions to the current problems so as to improve the development of sports industry and promote the overall development of sports population.
\end{abstract}

\section{SWOT analysis method is an enterprise's internal strategy analysis method.}

According to the existing conditions, the analysis of the internal environment of the advantages and disadvantages, the external environment threats and opportunities. S represents strength, W represents weakness, $\mathrm{O}$ represents opportunity, $\mathrm{T}$ represents threat. $\mathrm{S}, \mathrm{W}$ is internal factor, $\mathrm{O}, \mathrm{T}$ is external factor. Combining the SO, WO, ST and WT matrix, we can clearly analyze the resource advantages and defects of the object. Forecast the opportunities and challenges that will be faced, so as to adjust the methods and resources at both strategic and tactical levels. In order to ensure the achievement of the objectives. SWOT analysis is also called the situation analysis, is the early 1980s by the University of San Francisco, Professor of Management to a objective and accurate analysis and study the development of the reality of the method.

\section{Determination and Evaluation of SWOT Analysis Factors}

\subsection{SWOT analysis elements to determine}

SWOT analysis of the elements of the SWOT analysis model is an important condition and the key content of the existing conditions, the contents of a variety of indicators of comparison, generally including the status of the internal elements and external environmental factors. Different elements of the analysis of the composition of the industry is not the same content, such as the sports industry need to consider the SWOT elements of analysis: the quality of personnel, social environment, training programs, the economic environment. We take the Chinese Football Association Super League (CSL) business model as the research theme, determine the internal elements and external factors(Table 1).After determining the SWOT analysis elements, according to the elements of data integration and collection, in order to ensure the comprehensive and accurate analysis, after the preliminary analysis of the elements of the internal status and external environment for continuous improvement and supplement. 
Table 1 The SWOT Analysis Model Elements of the Operation Mode of CSL

\begin{tabular}{cc}
\hline Internal status elements & External environmental elements \\
\hline Talent quality & $\begin{array}{r}\text { Economic environment: Advertising sponsorship, } \\
\text { commercial sponsorship }\end{array}$ \\
Environment & $\begin{array}{r}\text { Government attitudes: Support, attention to attitude } \\
\text { Training program model } \\
\text { Competition Mechanism and } \\
\text { Professional Competition System }\end{array}$ \\
\end{tabular}

\subsection{Analysis and Evaluation SWOT elements}

In this paper, SWOT analysis method is adopted. The data samples from the recent years have comparable data, to ensure the credibility of the analysis model. At the same time, this method establishes the analysis model after contrasting and analyzing the elements of the sample, and gets the advantages, disadvantages, opportunities and threats of the operation mode of the Chinese professional league. After analyzing and comparing the elements of Chinese professional super league, the result of SWOT analysis is qualitatively evaluated.

Table 2: Operational Results of CSL Qualitative Assessment Results for SWOT Analytic Elements

\begin{tabular}{|c|c|c|c|}
\hline Advantages (S) & Disadvantages (W) & Opportunity (O) & Threat (T) \\
\hline $\begin{array}{l}\text { Advertising } \\
\text { sponsorship }\end{array}$ & $\begin{array}{l}\text { Administrative } \\
\text { interference }\end{array}$ & $\begin{array}{l}\text { Social environment } \\
\text { and harmony }\end{array}$ & Sports population decreased \\
\hline $\begin{array}{l}\text { Commercial } \\
\text { investment }\end{array}$ & $\begin{array}{l}\text { Market development is } \\
\text { imperfect }\end{array}$ & governmental support & $\begin{array}{l}\text { Oriented education } \\
\text { oppression }\end{array}$ \\
\hline $\begin{array}{c}\text { promote economic } \\
\text { development }\end{array}$ & Weak technical aspects & League system reform & $\begin{array}{c}\text { Foreign competition system } \\
\text { perfect }\end{array}$ \\
\hline $\begin{array}{l}\text { Derived subsidiary } \\
\text { products }\end{array}$ & Talent supply shortage & Perfect venue size & $\begin{array}{c}\text { Competitive level is difficult } \\
\text { to upgrade }\end{array}$ \\
\hline
\end{tabular}

\subsection{Advantages of the Chinese Professional League's Operating Model (S)}

The core of China's sports industry is based on the athletic league-based sporting events, the league operating company as an intermediate part of the club system will form the event resources and consumer connections in the sports association supervision, Commercial sponsorship, investment and tournament dividends. At the same time, the event operations can also profit from derivative products, such as sporting goods, sports lottery, sports marketing and other industries have a strong role in driving the sports industry.

2.22 Disadvantages of the Chinese professional league's operating model (O)

\section{A. Government interference}

The sponsor of the league is the sports administration department, the government position to control the absolute management of sporting events, sports association's goal is to maximize the absolute public interest, and each club is to maximize the interests of capital, the interests of the association and the club is inconsistent In the case of conflict between the two goals hinder the development of the league.

B. Insufficient market development

The main administrative body is one of the beneficiaries of the event, the vast majority of the 
club is still at a loss. Operation, the State Association is responsible for the organization and management, supervision and leadership of the General Administration of Sport, League-owned company development and maintenance, lack of market competition, low operating efficiency.

C. Weak technical links

As the technical level of the domestic league and abroad there is still a big gap between the competitive level of competition and lack of attractiveness, leading to the demand for sports consumption gap can't be filled, the current low awareness of domestic sports consumption.

D. Insufficient talent supply

From the Chinese youth soccer player 37051 in 2010 to only 7,000 in 2010, a substantial decline in the number of players in 10 years, although in 2011 increased to 20,000 or so, but the fact that football talent fault without question.

2.23 Opportunity (W)

China's sports industry has maintained a relatively rapid growth in recent years. The added value of the sports industry in 2007-2013 will be 356.3 billion yuan in 2013, an increase of 13.6 percent over the same period of last year and a compound annual growth rate of 20.2 percent in 2007-2013. The national strategy will strive to increase the amount of economic growth in the economy as an important tool for expanding national employment, enhancing industrial added value and enhancing national strength. The State Council issued a document, by 2025, the total size of China's sports industry reached 5 trillion.(Table 3)

The Chinese Football Association also proposed the overall reform and development of Chinese football program, the program put forward the "three-step" strategy, divided into short-term, medium-term and long-term goals: short-term goal is to straighten out the football management system, develop football long-term development plan, innovation with Chinese characteristics Football management model. Medium-term goal is to achieve a substantial increase in youth football population, professional league organization and competition level to Asia first-class, the national soccer team among the forefront of Asia, Women's football team to return to the ranks of world-class teams. The long-term goal is to make China a successful bid to host the World Cup soccer, soccer team scored the World Cup, into the Olympic Games.

Table 3 2007-2013 China's sports industry added value

\begin{tabular}{ccc}
\hline Year & $\begin{array}{c}\text { Sports industry added value }(100 \\
\text { million RMB) }\end{array}$ & $\begin{array}{c}\text { growth } \\
\text { rate }\end{array}$ \\
\hline 2007 & 1265 & $28.7 \%$ \\
2008 & 1555 & $22.9 \%$ \\
2009 & 2100 & $35.1 \%$ \\
2010 & 2220 & $5.7 \%$ \\
2011 & 2740 & $23.4 \%$ \\
2012 & 3136 & $14.5 \%$ \\
2013 & 3563 & $13.6 \%$ \\
\hline
\end{tabular}

\subsection{Threats $(\mathrm{T})$}

Compared with the Western countries, the establishment of China Super League short time, the league system and the competitive system is imperfect, competitive level is difficult to enhance the management mode of a single, which is the development of football career bottlenecks one of the reasons. Chinese and foreign tournament revenue scale and structure of the gap between China's top event group has not yet formed. For example, the Premier League's business model has been the development of diversified level, the purpose of operating football has been maximized from the public to maximize the operator's capital profits, its leading position in the world, has a large number of clusters. The rapid development of the global economy under the impact of the development of China's sports industry need to find a breakthrough in planning a local industry to adapt to the development of strategic programs. 


\section{Research on the application of model combination based on SWOT matrix analysis in Chinese Professional League}

After qualitative evaluation of the elements of SWOT analysis, according to the professional league's strengths, weaknesses, opportunities, threats of alignment and integration, using the AWOT matrix table lists the combinations of SO, WO, ST, WT. The various factors that will be investigated in accordance with the impact of intensity sort, and those factors which have direct, important, large and long-term effects on the development of the enterprise are prioritized.

Advantage - Opportunity (SO) strategy is a strategic way for Chinese professional leagues to give full play to their internal advantages and make rational use of external development opportunities.

Disadvantages - Opportunity (WO) strategy is to make full use of external development opportunities in the process of China's professional league in order to make up for its weaknesses.

Advantage - Threat (ST)strategy is a strategic approach to the development of Chinese professional league as much as possible using their own advantages,to avoid the threat of external environment.

Disadvantage - threat (WT) strategy is a way to reduce or eliminate the weakness of the Chinese Professional League in the process of operation, and to improve its own advantage to reduce the external threat.

After completing the SWOT matrix construction, according to the situation to develop a corresponding action plan. Follow the advantage factors, to overcome the weak factors, to use opportunity factors, based on the current focus on the future. The choice of the SWOT portfolio strategy, to put forward all-round of ideological and strategic objectives. In the thought, we should make clear the specific measures, such as management measures, safeguard measures, policies and service measures. Using the SWOT analysis method to combine the social development present situation, the management pattern of Chinese Football Super League want to get a breakthrough development, may use the SO strategy, give full play to the internal advantages, reasonable use of external opportunities. China's sports industry is growing stronger, China Super League as the highest level of China occupation football league, bringing the national huge commercial value and rich sportsmanship, drawing the development of sports lottery, sports goods industry. In the business model has been improved under the reasonable use of internal advantages to play a greater value.

To neighboring countries for reference, the development of foreign sports industry has been inspired. Such as a perfect case by using SWOT analysis model - the United States Madison Square Garden, its management model to fully develop the internal advantages and to seize external opportunities, such as high utilization ratio in venue, focusing on user-oriented experience, quality content, strong media. Madison Square Garden because of the strong property value. Its numerous venues and facilities, such as considerable advantages for sports competitions, cultural performances, by renting to the third party hosted entertainment venues to improve operational efficiency. Garden business model perfect to meet the user experience and the needs of network users, they put-off on-site interactive and mobile video playback and other high-definition applications to facilitate the fans to observe the ball when real-time communication. Its humanized software facilities is clearly showed in field link. Garden held high-quality events stimulating fares, attendance and sponsorship advertising. The team players have a great influence, high visibility and a high level of competition.

\section{Summary}

In this paper, SWOT analysis model is applied to study the Chinese sports industry, and SWOT analysis model is mainly used to analyze the characteristics of SWOT. The most representative Chinese football super league operational data is used as the sample to do the empirical research. Through the above research, it is found that Chinese sports league can develop rapidly under the advantage of commercial advertisement and national policy support, but the internal operation and 
management scheme has limitations. In order to improve the development of Chinese sports super league, this paper obtains by SWOT analysis model research The following recommendations: open the right to broadcast the event, the abolition of the monopoly of CCTV, according to the principle of market demand to establish sports events broadcast program. Enrich the market supply, strengthen the structure of sports facilities, expand the scale of China's sports league, the development of sports services. Attract more people to participate in sports fitness, improve the quality of sports population.

\section{References}

[1]. Qi Hailiang. The SWOT Analysis on the Development of Traditional Chinese Sports Culture[j].Bulletin of Sport Science \& Technology. （2016-04）

[2]. Zhang Huanyu ;Wan Shangqin; LI Dan .The Application of SWOT Analysis Method in Agricultural Development Strategy Research - Taking Hunan Agricultural Product Processing Development Strategy as an Example[j]. Chinese Journal of Tropical Agriculture. ( 2010-02)

[3]. Du Guangyou;Guo Min. Research on the System Reform of China Football Super League. Journal of Tianjin Institute of Physical Education. (2005-03)

[4]. Zhang Aibo .Comparative Research Study in Business Model Of England League and Chinese Super League. Master's thesis. Shenyang Institute of Physical Education. 2013.

[5]. Sports Writing Group. Introduction to Sports[M]. Beijing Sport University Press.2013. 